\title{
Obesity and male infertility: Mechanisms and management
}

\author{
Kristian Leisegang $^{1}$ (D) | Pallav Sengupta ${ }^{2}$ (D) | Ashok Agarwal ${ }^{3}$ (D) | Ralf Henkel R $^{3,4}$
}

\author{
${ }^{1}$ School of Natural Medicine, University of \\ the Western Cape, Cape Town, South Africa \\ ${ }^{2}$ Department of Physiology, Faculty of \\ Medicine, Bioscience and Nursing, MAHSA \\ University, Selangor, Malaysia \\ ${ }^{3}$ American Center for Reproductive \\ Medicine, Cleveland Clinic, Cleveland, $\mathrm{OH}$, \\ USA \\ ${ }^{4}$ Department of Medical Bioscience, \\ University of the Western Cape, Cape Town, \\ South Africa \\ Correspondence \\ Kristian Leisegang, School of Natural \\ Medicine, University of the Western Cape, \\ Cape Town, South Africa. \\ Email: kleisegang@uwc.ac.za
}

\begin{abstract}
Obesity is considered a global health problem affecting more than a third of the population. Complications of obesity include cardiovascular diseases, type 2 diabetes mellitus, malignancy (including prostatic cancer), neurodegeneration and accelerated ageing. In males, these further include erectile dysfunction, poor semen quality and subclinical prostatitis. Although poorly understood, important mediators of obesity that may influence the male reproductive system include hyperinsulinemia, hyperleptinemia, chronic inflammation and oxidative stress. Obesity is known to disrupt male fertility and the reproduction potential, particularly through alteration in the hypothalamic-pituitary-gonadal axis, disruption of testicular steroidogenesis and metabolic dysregulation, including insulin, cytokines and adipokines. Importantly, obesity and its underlying mediators result in a negative impact on semen parameters, including sperm concentration, motility, viability and normal morphology. Moreover, obesity inhibits chromatin condensation, DNA fragmentation, increases apoptosis and epigenetic changes that can be transferred to the offspring. This review discusses the impact of obesity on the male reproductive system and fertility, including associated mechanisms. Furthermore, weight management strategies, lifestyle changes, prescription medication, and complementary and alternative medicine in the management of obesity-induced subfertility is discussed.
\end{abstract}

\section{KEYWORDS}

male infertility, metabolic syndrome, obesity, semen quality

\section{1 | INTRODUCTION}

\section{1 | Clinical characterisation of obesity}

Obesity is characterised as an accumulation of excess body fat that has a detrimental impact on health outcomes and is clinically defined based on the body mass index (BMI), measured as weight ( $\mathrm{kg}$ ) divided by height (meters) squared $\left(\mathrm{kg} / \mathrm{m}^{2}\right.$ ) (World Health Organization, 2000). The BMI is recommended by the World Health Organization (WHO) to clinically classify weight and determine clinical risk (Table 1) (McPherson \& Lane, 2015). Within this system, obesity is defined as having a BMI of $>30 \mathrm{~kg} / \mathrm{m}^{2}$, while morbid obesity is defined as having a BMI of $>35 \mathrm{~kg} / \mathrm{m}^{2}$ (Okorodudu et al., 2010). However, the type and distribution of body fat accumulation are of clinical importance in the assessment of the risk of obesity-related complications (Alberti et al., 2009). In fact, BMI does not consider lean body mass and fat mass proportions, nor the distribution of detrimental visceral adiposity (white adipose tissue) and protective subcutaneous adipose tissue. BMI is therefore considered to have a low sensitivity to appropriately determining adiposity and may underestimate or overestimate the risk of obesity in a significant proportion of the population (Okorodudu et al., 2010).

The use of body fat percentage provides insight into the lean and fat mass ratios, differentiated between genders. The accepted consensus for increased risk of adiposity complications is $>25 \%$ in males and $>30 \%$ in females (Adler, Cassidy, Fricke, \& Bonduriansky, 2013). Waist circumference, however, most closely reflects visceral adiposity. It is measured around the abdomen at the mid-point between the 
anterior superior iliac spine and lowest potion of the costal margin, and accepted cut-off values range from 88 to $94 \mathrm{~cm}$ depending on ethnicity and gender (Alberti et al., 2009). This is currently considered as the most sensitive clinical risk marker for adiposity-induced complications (World Health Organization, 2000).

Complications of obesity rise exponentially with visceral adiposity. Common complications include cardiovascular disease (CVD), type 2 diabetes mellitus (T2DM) and various cancers, alongside accelerated ageing, neurodegeneration and a negative impact on human reproduction. These appear to be mediated through complex and poorly understood mechanisms, including insulin resistance (hyperinsulinemia), hyperleptinemia, chronic systemic low-grade inflammation and oxidative stress, as illustrated in Figure 1 (Leisegang, Henkel, \& Agarwal, 2019).

\section{2 | Epidemiology of obesity}

Obesity is considered a global health problem (Davidson, Millar, Jones, Fatum, \& Coward, 2015), with a significant global increase reported between 1980 and 2013 in men (28\%-36\%) and women (29\%-38\%) (Ng et al., 2014). An estimated 1.4 billion people are currently considered as overweight or obese, including over 200 million obese males (Davidson et al., 2015). This is expected to increase to more than $40 \%$ of the global population by 2030 (Kelly, Yang, Chen, Reynolds, \& He, 2008). In 2013, obesity was controversially recognised as a disease by the American Medical Association (AMA), with a significant consensus that obesity is a pandemic that requires prevention and management due to the co-morbidities and complications (Meldrum, Morris, \& Gambone, 2017). This is predominantly driven by an obesogenic environment, mediated through energydense food, high sugar intake, societal structure that reduces physical mobility and inexpensive nonphysical activities such as television, video games and social media (Meldrum et al., 2017).

\section{3 | Risk factors}

Polygenetic predisposition, particularly through single nucleotide polymorphisms (SNPs) and epigenetic inheritance, alongside ageing (mediated predominantly through oxidative stress) and female gender are considered as significant nonmodifiable risk factors of obesity (Leisegang, Henkel, \& Agarwal, 2017). Other risk factors include poor socio-economic status, psychological factors and reduced quantity or quality of sleep (e.g. night-shift workers) (Haslam $\&$ James, 2005). Importantly, the most significant risk factor for obesity is poor nutritional options (increased energy-dense foods) and a sedentary lifestyle within the context of an increasingly obesogenic and industrialised environment. (Castro, Macedo-de la Concha, \& Pantoja-Meléndez, 2017). This is predominantly observed in socalled 'Westernized' regions that are closely correlated with the obesity pandemic (Haslam \& James, 2005). Numerous prescription medications are also associated with obesity risk, including thiazide

\section{Author's Perspective}

\section{Key points}

- Obesity is associated with reduced fertility potential in males.

- Increased visceral adiposity affects steroidogenesis and spermatogenesis locally (testicular dysfunction) and peripherally (hypogonadism, inflammation and oxidative stress).

- Sperm DNA integrity and epigenetic modifications are important considerations in obesity related infertility management.

- Metabolic co-morbidities such as hyperinsulinemia, hyperleptinemia, systemic inflammation and oxidative stress are important metabolic mediators of obesity induced infertility in males.

- Improvement of adiposity improves fertility outcomes.

\section{Potential areas of research}

- The mechanisms of inflammation and oxidative stress in obesity related reproductive dysfunction?

- The potential role of antioxidants and immunomodulation as a novel therapeutic strategy in male induced subfertility?

- Evidence based guidelines for obesity reduction to improve fertility and ART outcomes?

- An optimal nutritional strategy to improve the impact of obesity on male reproductive system and fertility?

diuretics and beta-blockers (hypertension), thiazolidinedione agents and insulin (type 2 diabetes mellitus), tricyclic and monoamine oxidase inhibitors (antidepressants), anti-psychotics, oral contraceptive pills and glucocorticoids (Wofford, King, \& Harrell, 2006). However, the mediators of obesity and related complications remain complex within an obesogenic environment (Leisegang et al., 2019) (Figure 1).

\section{4 | Obesity: A key component of metabolic syndrome}

Metabolic syndrome is defined as a cluster of metabolic derangements that increases the risk for cardiovascular disease, type 2 diabetes mellitus and various malignancies, among other disorders. The most widely accepted diagnostic criterion requires the presence of three of the following five identified features: increased waist circumference (obesity), hypertension, low HDL-cholesterol, increased triglycerides and glucose intolerance. Cut-off values are different based on genetic predisposition and gender (Alberti et al., 2009). Obesity is just one of five diagnostic features, and therefore 
TABLE 1 Body mass index (BMI) categories and risk of co-morbidities

FIGURE 1 Risk factors, mechanisms and male reproductive outcomes in obesity. $\mathrm{E}_{2}, 17 \beta$-oestradiol; $\mathrm{T}$, testosterone

\begin{tabular}{|c|c|c|c|}
\hline BMI & Category & Complication risk & Complications \\
\hline$<18.5$ & Underweight & Increased & $\begin{array}{l}\text { Immunodeficiency; infectious } \\
\text { disease; malignancies }\end{array}$ \\
\hline $18.5-24.9$ & Optimal weight & Low & Uncommon \\
\hline $25.0-29.9$ & Overweight & Mild & \multirow{4}{*}{$\begin{array}{l}\text { CVD; T2DM; neurodegeneration; } \\
\text { malignancies }\end{array}$} \\
\hline $30.0-34.9$ & Obesity (Class I) & Moderate & \\
\hline $35.0-39.9$ & Obesity (Class II) & Severe & \\
\hline$>40$ & Obesity (Class III) & Very severe & \\
\hline
\end{tabular}

Abbreviations: CVD, cardiovascular disease; NCCDs, noncommunicable chronic diseases; T2DM, type 2 diabetes mellitus.

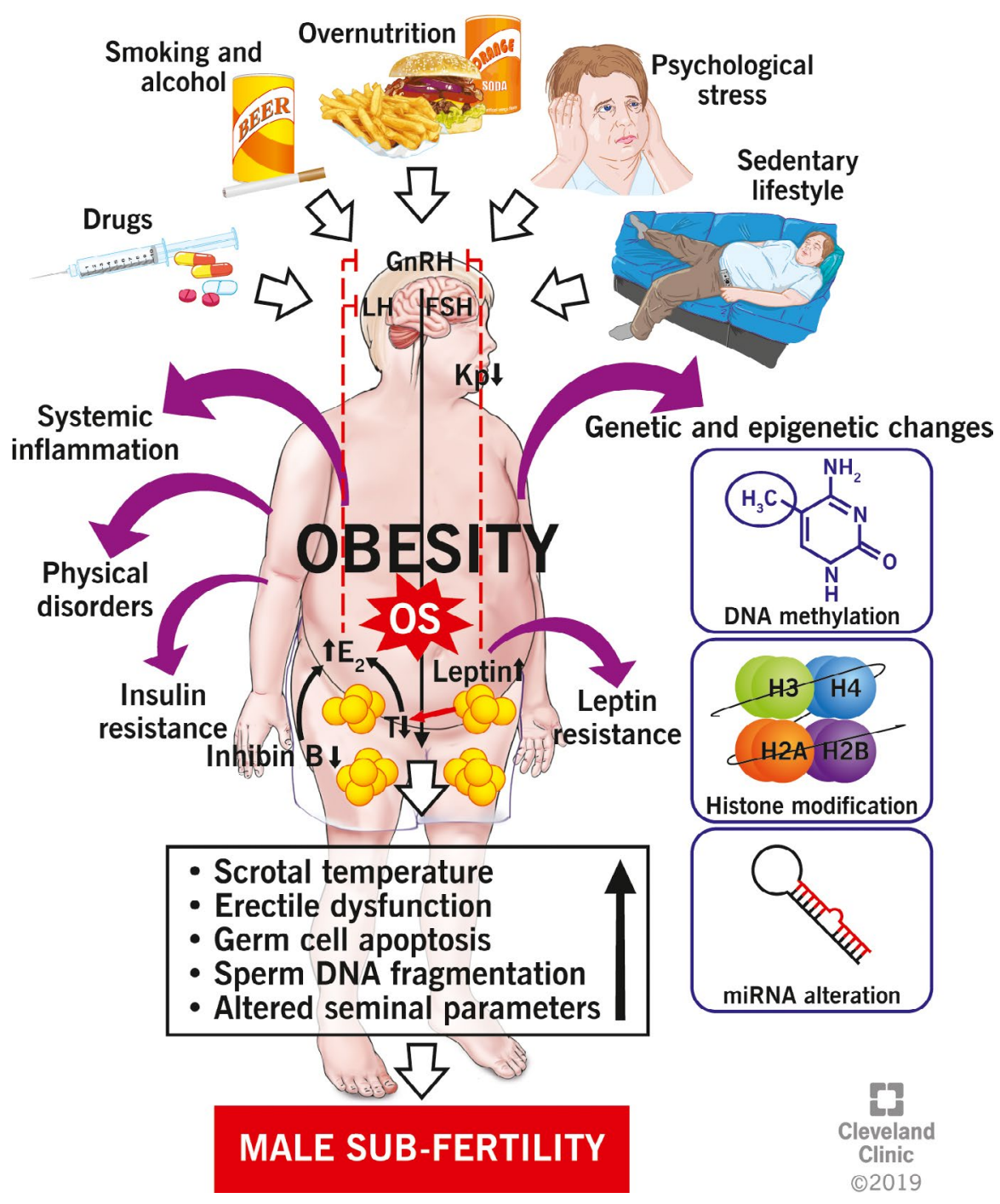

normal-weight individuals could have metabolic syndrome, and conversely, patients who are considered as overweight and obese but do not have the metabolic syndrome phenotype, may be at a lower risk for its complications (Alberti et al., 2009).

The co-morbidities and complications of obesity and metabolic syndrome are similar. Co-morbidities include obstructive sleep apnea, nonalcoholic fatty liver disease (NAFLD), microvascular disease and vasoconstriction. Complications include CVD, T2DM, malignancy (including prostatic cancer), neurodegeneration and accelerated ageing (McPherson \& Lane, 2015). In males, these further include erectile dysfunction, poor semen quality and subclinical prostatitis (Leisegang et al., 2019). These complications are mediated through common underlying mechanisms that are poorly understood, including metabolic, hormonal and immune dysfunctions such as insulin resistance (hyperinsulinemia), leptin resistance (hyperleptinemia), low-grade chronic inflammation and oxidative stress (Huang, 2009) (Figure 1). In males, obesity and metabolic syndrome are associated with hypogonadism as a common feature, thereby 
further increasing the risk for infertility and perpetuating the underlying mechanisms of obesity-induced complications (Du Plessis, Cabler, McAlister, Sabanegh, \& Agarwal, 2010).

\section{2 | IMPACT OF OBESITY ON MALE REPRODUCTION}

\section{1 | Obesity and hormonal imbalances}

\subsection{1 | Hypothalamic-pituitary-gonadal axis}

Physiological alterations induced by obesity that adversely affect the male reproductive endocrine system are mediated primarily through the hypothalamic-pituitary-gonadal (HPG) axis, the principal endocrine regulator of reproductive functions (Agarwal \& Dutta, 2020; Dutta, Sengupta, \& Muhamad, 2019). These HPG axis alterations are illustrated in Figure 1. Obesity is further associated with hypertrophy and hyperplasia of adipocytes, induction of adipokines secretion thereby altering endocrine regulation and testicular functions (Dutta, Biswas, \& Sengupta, 2019). In obese men, increased leptin secretion may also inhibit testosterone production by the Leydig cells (Caprio et al., 1999).

Increased adipose tissue depositions lead to an increased conversion of testosterone to estradiol (Hammoud, Gibson, Peterson, Hamilton, \& Carrell, 2006). This is mediated through excess production and hyper-activity of the aromatase cytochrome P450 enzyme in white adipose tissue (Katib, 2015). Obesity parameters such as BMI, total body fat percentage, percentage of subcutaneous fat and intra-abdominal fat are inversely correlated with low testosterone and directly correlated with high oestrogen levels in males (Tsai, Matsumoto, Fujimoto, \& Boyko, 2004).

The pulsatile release of hypothalamic gonadotropin-releasing hormone $(\mathrm{GnRH})$ result in the secretion of anterior pituitary gonadotropins, follicle-stimulating hormone (FSH) and luteinising hormone (LH) (Blache, Zhang, \& Martin, 2003). These gonadotropins are the key regulatory hormones acting upon the testicular cells. FSH acts upon the Sertoli cells to regulate spermatogenesis indirectly and stimulates synthesis of inhibin by the Sertoli cell. Inhibin acts directly through a negative feedback mechanism to downregulate pituitary FSH release. $\mathrm{LH}$ acts on the Leydig cells to upregulate steroidogenesis and testosterone synthesis. Testosterone further mediates spermatogenesis by its nuclear receptors in the Sertoli cell (Dutta, Sengupta, \& Muhamad, 2019).

Both oestrogen and testosterone act via an indirect negative feedback loop to the hypothalamic arcuate nucleus, where they downregulate KISS1neurons that secrete kisspeptin, thereby in hibiting GnRH release. Kisspeptin is well known for its role in establishing a link between metabolic and reproductive functions of hypothalamic neuroendocrine pathways (Wolfe \& Hussain, 2018). Besides stimulating $\mathrm{GnRH}$ release, kisspeptin is suggested to inhibit lipogenesis and induce lipolysis (Clarke, Dhillo, \& Jayasena, 2015). Thus, in obesity, decreased hypothalamic expression of kisspeptin
mRNA and KISS1may lead to suppressed pulsatile release of hypothalamic $\mathrm{GnRH}$, causing hypothalamic hypogonadism (Wolfe \& Hussain, 2018).

\subsection{2 | Testicular steroidogenesis}

Obesity-induced impairment in the sex hormone levels leads to adverse changes in testicular functions. Oestrogen is biologically more active than testosterone, therefore, a subtle increase in estradiol levels may have more of an inhibitory effect on testicular function compared with an increase in testosterone levels (Hammoud et al., 2006). Oestrogen regulates the overproduction of testosterone by limiting the levels of active testosterone in normal-weight men (Schulster, Bernie, \& Ramasamy, 2016). Oestrogen receptor expression in the male hypothalamus indicates that increased oestrogen levels in obese men elicit the negative feedback mechanism to inhibit pulsatile $\mathrm{GnRH}$ release. This in turn leads to subsequent insufficiency of $\mathrm{LH}$ and FSH for steroidogenesis and spermatogenesis (Chimento, Sirianni, Casaburi, \& Pezzi, 2014). The elevated oestrogen and induced systemic inflammation may influence steroidogenesis in the Leydig cells. It is plausible that the proteins mediating cholesterol uptake into the mitochondria, such as the steroidogenic acute regulatory (StAR) protein, key steroidogenic enzymes (P450scc, 3 $\beta \mathrm{HSD}$ and $17 \beta \mathrm{HSD}$ ) are negatively affected by increasing concentrations of inflammatory cytokines (Leisegang \& Henkel, 2018). Inhibin B, a growth-like factor secreted by Sertoli cells, also inhibits FSH secretion. Obese men have suppressed inhibin B production thereby disrupting the feedback loop of the HPG axis. This suggests that, besides impairment of steroidogenesis, obesity-mediated hormonal modulation has a direct adverse impact on the Sertoli cells (Salazar, Sánchez, Álvarez, Frusch, \& Mejía, 2018).

\subsection{3 | Metabolic hormone imbalances}

Excess white adipose tissue contributes significantly to the alterations in endocrine regulation leading to male reproductive dysfunction. Increased oestrogen levels together with the surge of an array of adipose tissue secretions interfere with the reproductive hormonal control over testicular functions (Bessesen, Hill, \& Wyatt, 2004). Adipose tissues serve as a source of hormones, adipokines, pro-inflammatory cytokines, as well as endogenous and exogenous toxins. In obese men, major adipokines, such as adiponectin (Dutta, Sengupta, \& Biswas, 2019), ghrelin (ÁlvarezCastro, Pena, \& Cordido, 2013), leptin (Ahima, 2008), orexin (PerezLeighton, Butterick-Peterson, Billington, \& Kotz, 2013), obestatin (Irez, Karkada, Dutta, \& Sengupta, 2019) and inflammatory cytokines (Leisegang \& Henkel, 2018) disrupt normal reproductive hormonal regulation.

Leptin, the key regulatory adipokine, is synthesised and secreted primarily in adipocytes and has a central function in the homoeostasis of energy intake and expenditure. Positively correlated with body 
fat mass, hyperleptinemia modulates male reproductive function (Malik, Durairajanayagam, \& Singh, 2019; Sengupta, Bhattacharya, $\&$ Dutta, 2019). Despite the essentiality of leptin for normal reproductive function, in excessive levels, it can severely affect male reproduction. The collective observations from studies in human and experimental animal suggest that leptin can serve to understand the possible association between infertility and obesity (Almabhouh, Aziz, Durairajanayagam, \& Singh, 2020; Almabhouh, Md Mokhtar, et al., 2020). Leptin may act via its receptors on the KISS1 neurons, stimulating $\mathrm{GnRH}$ release from the hypothalamus. KISS1 neurons project to both GnRH neurons as well as to the NPY neurons (Ojeda et al., 2006). Thus, leptin can prevent GnRH inhibition by the NPY neurons, acting through KISS1. It is hypothesised that obese men may develop leptin resistance, which may lead to the suppression of KISS1 neuron activities and increased NPY levels, causing an inhibition of GnRH neurons (Ojeda et al., 2006). This eventually affects the release of gonadotropins from the pituitary, reducing steroidogenesis and resulting in hypogonadotropic hypogonadism (Teerds, Rooij, \& Keijer, 2011).

It has also been reported that deficiency of the functional leptin gene may result in decreased gonadotropin secretion thereby affecting fertility parameters, while exogenous leptin administration could significantly improve fertility (Mounzih, Lu, \& Chehab, 1997). Leptin deficiency in mice has shown impaired spermatogenesis and high rates of germ cell apoptosis (Bhat et al., 2006). These evidences indicate that leptin is vital for maintaining normal testicular activities. However, excessive leptin secretion in obese men inhibits testicular functions (Ramos \& Zamoner, 2014), possibly by inducing uncontrolled production of reactive oxygen species (ROS) in endothelial cells by elevated mitochondrial fatty acid oxidation (Yamagishi et al., 2001).

In obese men, the levels of serum adiponectin are elevated and it bears an inverse association with testosterone (Page et al., 2005). In addition, orexin (hypocretin) which is one of the nonclassical metabolic hormones have been shown to stimulate testosterone production by increasing the activities of the steroidogenic enzymes in Leydig cells (Zheng et al., 2014). Orexin also plays a role in ameliorating cellular oxidative damage (Duffy, Nixon, \& Butterick, 2016). Obesity is associated with reduced levels of orexins and thereby disrupts the balance between energy homoeostasis and reproductive functions in men (Sengupta, Dutta, Tusimin, \& Karkada, 2019).

Resistin, an adipose tissue-specific secretory factor, is substantially increased by obesity-induced excess adipose tissues. It reportedly impairs the glucose uptake ability of the adipose cell, elevates blood glucose levels, and thereby reduces insulin sensitivity in obese men. There are studies that support that resistin can induce type 2 diabetes in obese men (Flehmig et al., 2014).

Hyperinsulinemia in insulin-resistant obese men may cause decreased SHBG levels and testosterone levels which are needed for normal spermatogenesis. Hence, obese men suffering from type 2 diabetes may acquire secondary hypogonadism. This may reflect direct effect of insulin resistance on testosterone synthesis by the Leydig cells (Du Plessis et al., 2010).

Ghrelin is a neuropeptide secreted in the gastrointestinal tract and is referred to as the 'hunger hormone'. It has also been shown to be associated with impaired steroidogenesis and low serum testosterone levels (Wang et al., 2011). Its role in steroidogenesis is predicted via its receptor expressions in the testis, although any direct effect of ghrelin on spermatogenesis has not yet been reported (Ishikawa, Fujioka, Ishimura, Takenaka, \& Fujisawa, 2007). Increase in serum levels of ghrelin is associated with increased obesity-related complications (Dutta, Biswas, Sengupta, \& Nwagha, 2019).

\subsection{Obesity and spermatogenesis}

In the seminiferous tubules, there is a steady balance among germ cell growth, multiplication and apoptosis (Rooij, Alphen, \& Kant, 1986). Following the first spermatogenic wave, the germ cells begin to differentiate in a distinctive hormonal micro-environment. In cases of cell over-production, apoptosis is induced by activation of the Bcl- $X_{L}$ and Bax systems (Hikim \& Swerdloff, 1999). Spermatogonial apoptosis takes place only under specific conditions, and an array of regulatory genes determine its induction. A1spermatozoa have been shown to undergo a significantly increased rate of apoptosis in conditions of obesity. According to recent studies, dysregulation of apoptosis induction in spermatogenic cells is a major causative factor of male infertility (Garolla et al., 2013). Obesity may exaggerate the induction of apoptosis by impairing the conventional $\mathrm{Bax}$ and $\mathrm{Bcl}-2$ homoeostasis, such that the expression of $\mathrm{Bax}$ is highly increased while $\mathrm{Bcl}-2$ expression is suppressed. This leads to activation of downstream signalling caspases of the apoptotic pathway (Jia et al., 2018). Moreover, the state of hyperlipidemia also causes increased stress upon the endoplasmic reticulum, inducing further spermatogenic cell apoptosis by high expressions of binding immunoglobulin protein (BiP) ( $\mathrm{Li}$, Dong, Lan, Zhang, \& Li, 2015).

\section{3 | Obesity and semen quality}

Male fertility semen parameters primarily include sperm concentration and total sperm count, motility, viability and morphology, among others. Human semen quality serves as a predictor of male fertility, which is suggested to be declining in recent decades (Carlsen, Giwercman, Keiding, \& Skakkebæk, 1992; Sengupta, Dutta, et al., 2018; Sengupta, Dutta, \& Krajewska-Kulak, 2017). Overweight and obese males are reported to be associated mainly with an increased prevalence of oligozoospermia and azoospermia (Sermondade et al., 2013). Obesity potentially induces bodily alterations and hormonal modulations that adversely affect fertility parameters in men (Bieniek et al., 2016). Association of BMI with sperm functions have been studied extensively yet a complete understanding of the underlying mechanisms is still lacking (Chavarro, Toth, Wright, Meeker, \& Hauser, 2010; Hammiche et al., 2011; Sermondade et al., 2013).

Compared to normal-weight men, obese men have a threefold higher probability of oligozoospermia (concentration <15 million/ 
ml) (WHO, 2010). Chavarro et al. (2010) suggested that a high BMI $\left(>25 \mathrm{~kg} / \mathrm{m}^{2}\right)$ in men corresponds to poor total sperm count. The ejaculate volume is reduced with increased BMI (Jensen et al., 2004), and sperm motility and morphology are also severely impaired by obesity (Kahn \& Brannigan, 2017). These findings have been supported by other studies further emphasising the disruptive effects of obesity on sperm functions (Davidson et al., 2015).

\subsection{Obesity and sperm DNA integrity}

Obesity-induced alterations in sperm functions may be significantly associated with sperm DNA fragmentation (SDF). In obese men, sperm DNA integrity is adversely affected. Increased DNA fragmentation index (DFI) (percentage of spermatozoon with high single- or double-strand breaks in nuclear DNA, in a semen sample) is reportedly accompanied by high BMI, which demonstrate the association of obesity and SDF (Panner Selvam, Sengupta, \& Agarwal, 2020). It is suggested that the BMI more than $25 \mathrm{~kg} / \mathrm{m}^{2}$ corresponds to high sperm DFI. Obesity-induced testicular oxidative stress is a possible mechanism that can explain this scenario. Obesity may induce testicular OS via several potential mechanisms. Increase in fatty acid oxidation in mitochondria and peroxisome by adipose tissue accumulation lead to higher generation of ROS. Thus, higher ROS mediates oxidative damage to biomolecules that include lipids, proteins, and DNA. These cause oxidation of polyunsaturated fatty acids in sperm membrane, loss of mitochondrial membrane potential and single- and double-strand SDF (Panner Selvam et al., 2020). Maintaining sperm DNA integrity is essential for spermatozoa fertilising ability and successful pregnancy outcomes (Benchaib et al., 2007). In addition to the conventional semen parameters, analysis of SDF provides better understanding of the male fertility status. The importance of the SDF assay in male infertility cases has also been supported by the American Urological Association (AUA) and the European Association of Urology (EAU) guidelines (Jarow, Sigman, $\&$ Kolettis, 2011). Several reports have put forth possible clinical values for proper assessment of SDF in male infertility (Agarwal, Cho, \& Esteves, 2016; Agarwal, Majzoub, et al., 2016).

\section{5 | Obesity and erectile dysfunction}

Obese men have a 1.5-fold increased chance of developing erectile dysfunction (ED) (Sarwer, Hanson, Voeller, \& Steffen, 2018), which has been reported to have a positive correlation with male infertility (Du Plessis et al., 2010). Obesity may lead to erectile dysfunction by reduction in testosterone levels and eliciting a systemic inflammatory condition via release of inflammatory cytokines (Seftel, 2006). These inflammatory mediators directly induce endothelial cell dysfunction and via nitric oxide pathway they may lead to male erectile dysfunction (Yu, Li, Li, Zhong, \& Mao, 2017). Obesity is linked with several pathogenic conditions, such as diabetes, hypertension and dyslipidemia, which may be linked to the induction of ED (Shamloul
\& Ghanem, 2013). The exact mechanism of obesity-induced ED requires better understanding, especially in relevance to decreased libido, endocrine dysregulation and psychological disorders (Hammoud, Gibson, Peterson, Meikle, \& Carrell, 2008).

\section{3 | OBESITY-INDUCED GENETIC AND EPIGENETIC MODIFICATIONS}

Excessive adiposity negatively impacts DNA integrity and epigenetic regulation across a range of tissues, including adipose tissue, hepatic tissues, skeletal muscle, pancreas, hypothalamus, prostate and testes (Martins, Majzoub, \& Agawal, 2019). The altered testicular environment, dominated by inflammation and oxidative stress, reduces semen quality, modifies sperm membrane, mitochondrial lipids and induces DNA damage (Liu \& Ding, 2017). Particularly, a negative impact on spermatozoa chromatin condensation and DNA integrity has been reported, mediating a risk for pregnancy complications, such as spontaneous abortion and recurrent pregnancy loss, as well as an impact on assisted reproductive techniques (ART) outcomes (Leisegang, 2019; Leisegang et al., 2019). This is further observed in animal and human studies in males with metabolic syndrome (Leisegang, Bouic, \& Henkel, 2016; Leisegang, Udodong, Bouic, \& Henkel, 2014). Furthermore, the impact of epigenetic modification in sperm DNA in obese males is reported to increase the risk of obesity and metabolic derangements, neurological disorders (including attention deficit disorder) and various cancers in the offspring (Soubry et al., 2016). Although paternal epigenetic modification is known to be transferred to the next generation, causality has not yet been demonstrated.

Epigenetic modification is due to a reset in methylation marks which regulate gene expression (Figure 1). The process establishes paternal-specific methylation in the embryo development. This transfer of epigenetic modifications is also suggested to be through the action of noncoding RNA. Genes that undergo modification in paternal obesity include MEG3, NDN, SNRPN and SGCE/PEG10, which regulate foetal development and tumour growth (Soubry et al., 2016). However, limited pre-clinical evidence suggests that the epigenetic modifications are reversible with reduced adiposity (Setayesh et al., 2018).

\section{4 | MECHANISMS IMPLICATED IN OBESITY-INDUCED MALE INFERTILITY}

The complex pathophysiology of obesity involves chronic inflammatory responses together with endocrine disruptions among others. An obesogenic environment with an excessive deposition of visceral adipose tissues induces a $T_{h}$ 1-lymphocyte and M1-macrophage driven pro-inflammatory responses (Leisegang et al., 2019). This inflammatory response is characterised by modulation of cytokines, adipokines and myokines that adversely affect numerous tissues, including the hypothalamus, cardiac, hepatic, pancreas and testes. 
Male infertility and hypogonadism are among the major co-morbidities associated with obesity-induced systemic inflammation. Inflammatory mediators of this immune response include interleukin (IL)-1 $\beta$, IL6, IL8, IL12, tumour necrosis factor-alpha (TNF $\alpha$ ), interferon gamma (IFN $\gamma$ ), transforming growth factor-beta (TGF $\beta$ ), macrophage inflammatory protein (MIP-1), monocyte chemotactic protein (MCP-1), and neuroendocrine hormones, leptin and resistin (Figure 2) (Leisegang et al., 2019).

Leptin induces macrophage infiltration in tissues further eliciting the inflammatory responses. These may also lead to hypothalamic inflammation thereby affecting the release of hypothalamic releasing hormones and dysregulation of the HPG axis (Castro et al., 2017). The pathways involved in obesity-induced inflammation has been reported to involve activation of toll-like receptor 4 (TLR4), endoplasmic reticulum stress, mitochondrial dysfunction and serine/threonine kinase activation (Thaler \& Schwartz, 2010). The dyslipidemia state in obese men may cause testicular oxidative stress, which is a common established pathway for disruption of sperm functions (Biswas, D'souza, \& Bhat, 2017). Cellular processes may modify LDL functions to render it capable to act as a ligand for macrophage pattern recognition receptors, such as the toll-like receptors (TLRs). Thus, it directly induces pro-inflammatory signalling pathways to initiate the release of the pro-inflammatory mediators. The modified LDL may also be engulfed by monocytes, neutrophils and other macrophages, which lead to the accumulation of cholesterol in those cells. This further amplifies the TLR signalling cascades, worsening the inflammatory condition (Tall \& Yvan-Charvet, 2015). Obesity and metabolic syndrome may elicit reproductive tract inflammation owing to higher levels of pro-inflammatory cytokines as found in the prostate, seminal vesicles, testes, epididymis and ejaculate of obese men (Leisegang et al., 2016). This inversely correlates with indicators of hypogonadism and decreased semen quality (Leisegang et al., 2016). Moreover, hyperglycemia is another independent factor in the induction of oxidative stress and endoplasmic reticulum stress. This can cause inflammation that may result in glycation end-products and induce SDF (Maresch et al., 2017). C-reactive protein, another prominent inflammatory marker, is also markedly elevated in obesity-associated reproductive tract inflammation (Leisegang et al., 2019).

The obesity-associated inflammatory responses may disrupt the endocrine regulation of reproductive functions via affecting the HPG axis and its crosstalk with other hormones. The obesity-associated hormonal alterations mainly involve reduced levels of testosterone, progesterone and sex hormone-binding globulin (SHBG) levels and high levels of oestrogen that strongly inhibit the HPG axis so

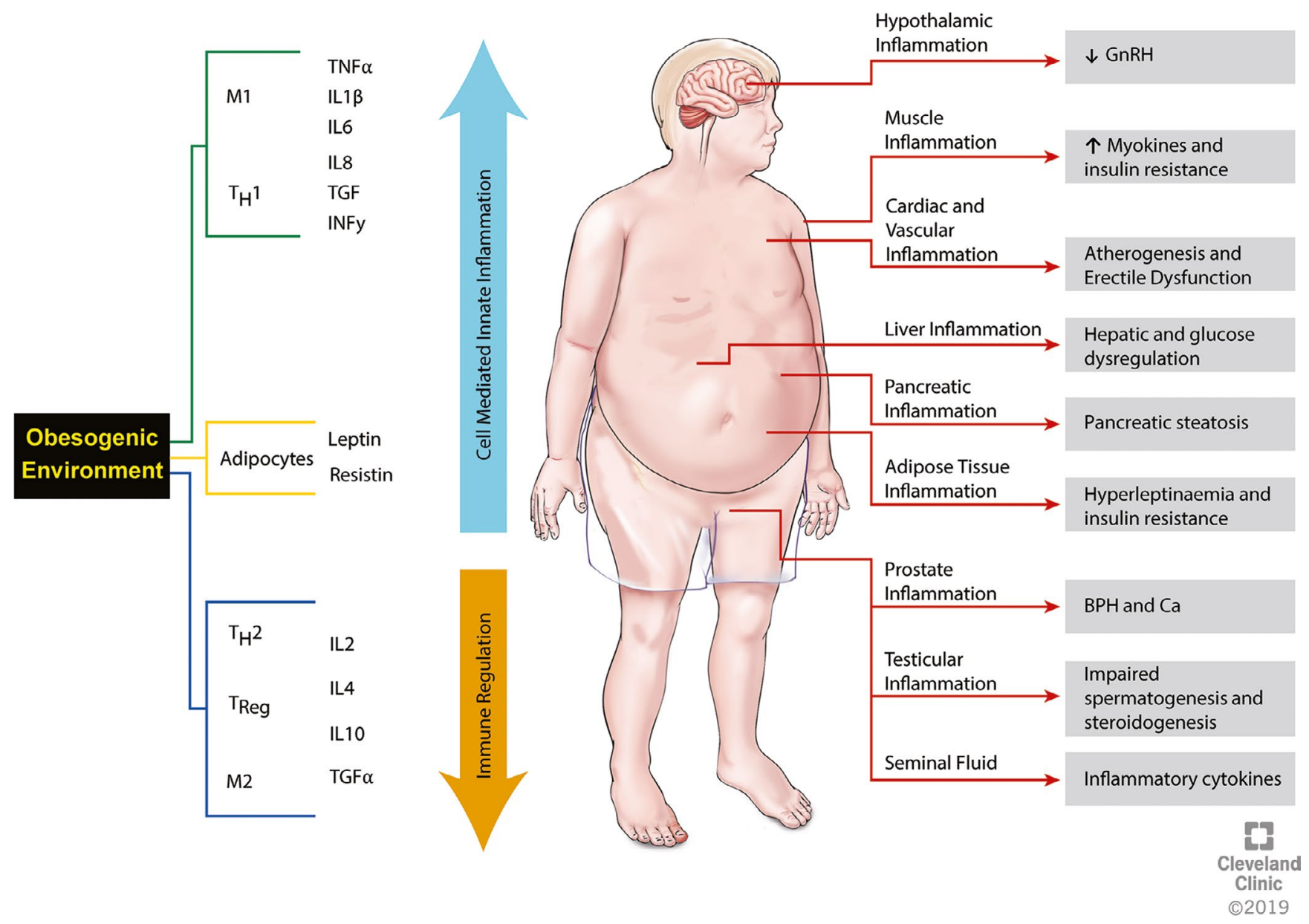

FIGURE 2 Low-grade systemic chronic inflammation associated with obesity 
that the release of hypothalamic $\mathrm{GnRH}$ and subsequent release of FSH and LH are inhibited (Leisegang et al., 2016). Since obesity is associated with excessive adipose tissue deposition, the adipose tissue-derived factors and several metabolic hormones also play a vital role in the modulation of hormonal crosstalk in obese men. Leptin resistance is a common phenomenon in obesity, leading to inhibition of $\mathrm{GnRH}$ and the subsequent $\mathrm{LH}$ and FSH release (Ojeda et al., 2006). Impaired regulation of testicular functions by $\mathrm{GnRH}$ and gonadotropin may explain the primary hormonal mechanism of obesity-associated male infertility. In addition, obese men suffer from physical disorders such as erectile dysfunction and high scrotal temperature that also contribute to male infertility (Du Plessis et al., 2010).

\section{5 | OBESITY AND ART OUTCOMES}

Nongenetic effects of long-term paternal health issues may affect the offspring by transmission via the male gamete (Soubry et al., 2013). Studies have reported that male obesity substantially affects the outcome of ARTs such as in vitro fertilisation (IVF) or intracytoplasmic sperm injection (ICSI). Rates of clinical pregnancy following ART are reduced in couples with an obese male partner (Schliep et al., 2015; Umul et al., 2015). The live birth rate following ART mediated pregnancy is also reduced in the case of paternal obesity (Schliep et al., 2015; Umul et al., 2015). Moreover, obesity in the male partner has also been reported to affect the child's development during infancy and early childhood period as reflected by the BMI growth curves from birth till the age of 3.5 years (Linabery et al., 2013). Thus, ART outcomes of couples with an obese male partner demonstrate decreased impregnation rate, live birth rates and compromised infant health.

\section{6 | MANAGEMENT OF OBESITY- ASSOCIATED MALE INFERTILITY}

Management of obesity-associated male infertility is complex due to the underlying pathophysiology and associated co-morbidities. Importantly, weight management strategies based on lifestyle amendments are recommended. However, treatment with various nutraceuticals and herbal (phyto) supplements may be warranted. Additional options include surgical and potentially prescription medications that either improve adiposity and/or improve the underlying mediators of obesity-related complications and infertility (Singh, Pragasam, \& Venkatesan, 2018).

\section{1 | Lifestyle modifications}

Reduced abdominal adiposity, independent of a change in BMI, has been demonstrated to reduce seminal oxidative stress and SDF (Håkonsen et al., 2011). In animal models, a reduction in paternal weight modifies metabolic derangements and reproductive parameters, improving embryo quality and foetal development. This further reduces the negative consequences on metabolic and fertility parameters in the offspring (Danielewicz, Przybyłowicz, \& Przybyłowicz, 2018).

A modern obesogenic or 'Westernized diet' is characterised by high energy sugars and refined carbohydrates, high total fat and hydrolyzed fatty acids consumption, with low consumption of fruits, vegetables, fibre and beneficial fatty acids. This dietary pattern is associated with poor semen parameters and fertility outcomes, including in healthy males (Salas-Huetos, Bulló, \& Salas-Salvadó, 2017). Optimal diets, such as the Mediterranean and similar 'prudent' diets, are demonstrated to improve obesity-associated metabolic derangements and male semen parameters. These diets include increased intake fruits, vegetables, favourable fatty acids (unsaturated and omega-3 polyunsaturated fatty acids), whole grains, fibre, as well as foods rich in antioxidants, micronutrients and other phytochemicals (Salas-Huetos et al., 2017). These nutrients are obtained from fruits and vegetables, seafood, oils, nuts and seeds. Importantly, these dietary patterns further correlate to improved fertility parameters across a range of $\mathrm{BMI}$ classifications, even in the absence of weight loss (Salas-Huetos et al., 2017).

Adherence to the Mediterranean diet improves sperm concentration, motility and morphology in humans (Karayiannis et al., 2017), and diets rich in fruits, vegetables, antioxidants, nuts, seeds and fish showed improved semen parameters, in large observational studies (Gaskins, Colaci, Mendiola, Swan, \& Chavarro, 2012). These dietary habits also improve DNA fragmentation, suggesting a benefit on embryo, foetal and offspring quality (Mir, Franken, Andrabi, Ashraf, \& Rao, 2018). It is proposed that the benefits of these nutritional sources on male fertility are due to antioxidant-rich foods which modulate positively inflammation and oxidative stress. Important antioxidants that are beneficial in combating male obesity and its associated infertility include $\beta$-carotenes, vitamins C, D and E, folate, selenium, zinc, L-carnitine, acetyl-carnitine and lycopene. Deficiency of these micronutrients is associated with oxidative stress in males (Leisegang et al., 2019). Furthermore, obesity is paradoxically associated with micronutrient deficiencies (MND) through nutrient-poor foods and the increased requirements for antioxidants. Common MND in obesity includes vitamin D, selenium, vitamin C, zinc, vitamin B1, $\beta$-carotenes, folate and vitamin $E$ (Alhashem et al., 2014). Supplementation with omega-3 fatty acids is reported to be associated with better testicular function (Jensen et al., 2020). However, there are currently no guidelines for optimal nutritional recommendations or antioxidant use in males across a range of BMI, although appropriate nutritional advice based on the Mediterranean diet for example, is warranted in the management of all male infertility cases.

Antioxidant-rich nutrition as described above is recommended as a primary source of the relevant antioxidants and micronutrients. However, the use of supplementation of specific or combined antioxidant treatments may also be considered. The aim of any supplementation is to restore appropriate redox balance without inducing reductive stress (Maneesh \& Jayalekshmi, 2006). The use of antioxidants in male reproduction, however, requires further investigation, 
as there is no consensus of the type, dosage and duration of treatment (Deepinder, Cocuzza, \& Agarwal, 2008). Evidence suggests that antioxidant treatment reduces DNA damage, improves fertility and ART outcomes (up to 4-times improvement), and reduces the risk of pregnancy complications and spontaneous abortions (Mora-Esteves \& Shin, 2013). Evidence further suggests that antioxidant treatment can improve fertility outcomes in obesity, mediated through improved semen parameters, endocrine regulation, immunomodulation and redox balance, independently of BMI and adiposity changes (Montanino Oliva, Minutolo, Lippa, laconianni, \& Vaiarelli, 2016). Antioxidants more commonly used in studies for male reproduction include vitamin A ( $\beta$-carotenes), B-vitamins, vitamin C (ascorbic acid) and E, coenzyme Q10, L-carnitine, $\alpha$-lipoic acid, glutathione, $N$ acetyl-cysteine, selenium, zinc and copper (Roychoudhury, Agarwal, Virk, \& Cho, 2017). The application of phytonutrients through appropriate medicinal herbs provide various secondary plant metabolites that benefit human health, including obesity and male fertility (Leisegang et al., 2017). Phytonutrients that show benefit in obesity and male fertility include Camellia sinensis (epigallocatechingallate), Curcuma longa (curcuminoids), Nigella sativa (thymoquinone), Panax ginseng and Panax quinquefolius (ginsengosides), Vitus vinifera (resveratrol) and Withania somnifera (withanolides) (Leisegang et al., 2019; Payab et al., 2019; Roychoudhury et al., 2017; Sengupta, Agarwal, et al., 2018.

Physical exercise is a critical and cost-effective strategy to manage obesity and co-morbidities, further improving overall health and sense of well-being (Sansone et al., 2018). However, excessive intensity or duration of exercise can be detrimental on male reproductive outcomes (Sansone et al., 2018). Exercise induces a rapid rise in testosterone, through increased pituitary activity, improved Leydig cell function and a reduction in testosterone clearance. However, excessively intense short-term and long-term exercise results in a reduction in serum testosterone over time (Sansone et al., 2018). Moderate exercise further improves sexual function and satisfaction in obese men, where increased fitness correlated with sexual desire and satisfaction. In fact, exercise is recommended as first-line treatment in erectile dysfunction (Shamloul \& Ghanem, 2013). This is relevant in the requirement for intercourse in natural conception (Sansone et al., 2018). Endurance exercise in obese rats reportedly improves visceral and epididymal adiposity, serum testosterone and gonadotropins, serum leptin and ghrelin, semen parameters and testicular oxidative stress (through increased superoxide dismutase and glutathione expression and reduction in thiobarbituric acid reactive substances) (Alhashem et al., 2014). Low-to-moderate exercise in obese fathers further mitigates the negative impact of epigenetic transfer to the offspring in rat models (McPherson \& Lane, 2015). Moderate endurance exercise in obese males is suggested to improve fertility parameters, including oxidative stress and DNA damage in spermatozoon. However, intense exercise is not recommended (Du Plessis et al., 2010). More recently, caloric restriction (CR) has gained attention in obesity and metabolic syndrome patients, as well as general health and wellness. This is defined as a reduction in total calorie (energy) intake that does not result in MND (Moatt, Nakagawa, Lagisz, \& Walling, 2016). In all mammals, including humans, CR has been demonstrated to increase lifespan through reduced age-related degeneration, as well as weight loss and improved metabolic regulation in obesity. CR also reduces the risk of complications such as CVD, T2DM, malignancies and neurodegeneration (Moatt et al., 2016). Although the mechanisms remain poorly understood, a significant contributor is the upregulation of endogenous antioxidant production and improved redox regulation through the ageing process (Barja, 2014). Importantly, the impact of CR in male fertility is not clear, with initial evidence suggesting a trade-off between longevity and reproduction potential in CR. However, long-term (5-7 years) CR investigation in Rhesus monkeys do not show any detrimental effect to semen parameters or reproductive hormones (Sitzmann et al., 2014). Therefore, studies in humans to determine the impact of $\mathrm{CR}$ on male reproduction in lean and obese males are warranted, although caution should be advised when using this approach based on the current evidence (Sitzmann et al., 2014).

\section{2 | Prescription medication}

Metformin is used in the management of insulin resistance and type $2 \mathrm{di}-$ abetes mellitus. Although some data are conflicting, evidence suggests that metformin provides benefit to male fertility (Ferreira et al., 2015). Metformin is associated with an improvement in semen parameters and fertility outcomes, including testicular weight and increased numbers of spermatogonia, Sertoli and Leydig cells. This is mediated through reduced apoptosis, protection against testicular inflammation and oxidative stress, and activation of the mitogen-activated protein kinase (MAPK) pathway (Ferreira et al., 2015; Ye et al., 2019).

Testosterone replacement therapy (TRT) improves obesity and metabolic-associated derangements and co-morbidities (Roth, Amory, \& Page, 2008), including immune modulation, reduced oxidative stress, improved insulin and leptin sensitivity, reduced adiposity and increased lean body mass (Winter, Zhao, \& Lee, 2014). However, excessive testosterone has a detrimental impact on spermatogenesis, primarily through the negative hormonal feedback. Therefore, TRT is not recommended for management of obese patients with desire for fertility (Roth et al., 2008; Winter et al., 2014). An alternative medication for improvement of hypogonadism in obese males is aromatase inhibitor (such as Letrozole and Anastrozole), which suppress the conversion of testosterone to oestrogen that is upregulated in obesity (Stephens \& Polotsky, 2013). These medications are associated with improved spermatogenesis and semen parameters; however, approval for use in male infertility is currently lacking (Roth et al., 2008). Clomiphene citrate (selective oestrogen receptor modulator) has been reported to improve testosterone in hypogonadal obese males (Bendre, Murray, \& Basaria, 2015; Ring, Lwin, \& Köhler, 2016). Human chorionic gonadotropic (hCG), a LH analog, has been reported to increase intratesticular and serum 
testosterone levels and maintain spermatogenesis in hypogonadal men, although the impact on adiposity in males is not clear (Ring et al., 2016).

\section{3 | Surgical interventions}

Although bariatric surgery has a significant effect on BMI, abdominal adiposity and metabolic derangements in obesity and metabolic syndrome, current evidence does not suggest a positive impact on male fertility parameters (Wei, Chen, \& Qian, 2018). In fact, bariatric surgery is suggested to potentially worsen semen parameters, where azoospermia and oligoasthenoteratozoospermia have been reported in the months following the procedure (di Frega, Dale, Matteo, \& Wilding, 2005; Sermondade et al., 2012). This may be induced by the release of lipophilic toxic substances due to rapid weight loss, which include endocrine disrupters stored in the excess adipose tissue through environmental exposures (Reis \& Dias, 2012; Wei et al., 2018). However, the medium and long-term impact of bariatric surgery on male reproduction requires further investigation (Wei et al., 2018).

\section{7 | CONCLUSION}

Alongside the declining global trend in male infertility, obesity has been significantly increasing over recent decades. Obesity is known to adversely affect male infertility through alteration in semen parameters (including sperm concentration, motility, viability, morphology, DNA integrity and mitochondrial function), endocrine changes (including hypogonadism, hyperinsuinemia and hyperleptinemia) and systemic and reproductive system inflammation and oxidative stress. An obesogenic environment may elicit inflammatory responses, where adipokines such as leptin modulate the HPG axis and male reproductive functions. Induction of oxidative stress is suggested to be a common pathway leading to disrupted male reproductive functions in obesity. In addition, obese men possess higher oestrogen than testosterone levels owing to increased aromatase activities, or by negative feedback mechanism of oestrogen to inhibit the pulsatile GnRH release and subsequent release of $\mathrm{LH}$ and $\mathrm{FSH}$. Obesity further induces sperm DNA damage, resulting in increased apoptosis, DNA fragmentation and epigenetic transfer to the offspring. Male obesity is also associated with reduced success in ART in clinical practice. Importantly, correction of obesity is suggested to reverse the impact on the male reproductive system. This is done through improved nutritional quality, increased appropriate exercise, consideration of micronutrient and phototherapy supplementation. Medical intervention can be considered, particular strategies to improves testosterone and oestrogen ratios such as aromatase inhibitors and selective oestrogen receptor modulators.

\section{ORCID}

Kristian Leisegang (iD https://orcid.org/0000-0002-3003-8048

Pallav Sengupta (iD https://orcid.org/0000-0002-1928-5048

Ashok Agarwal iD https://orcid.org/0000-0003-0585-1026

Ralf Henkel iD https://orcid.org/0000-0003-1128-2982

\section{REFERENCES}

Adler, M. I., Cassidy, E. J., Fricke, C., \& Bonduriansky, R. (2013). The lifespan-reproduction trade-off under dietary restriction is sex-specific and context-dependent. Experimental Gerontology, 48(6), 539-548. https://doi.org/10.1016/j.exger.2013.03.007

Agarwal, A., Cho, C. L., \& Esteves, S. C. (2016). Should we evaluate and treat sperm DNA fragmentation? Current Opinion in Obstetrics and Gynecology, 28(3), 164-171. https://doi.org/10.1097/GCO.00000 00000000271

Agarwal, A., \& Dutta, S. (2020). Obesity. In S. Parekattil, S. C. Esteves, \& A. Agarwal (Eds.), Male infertility: Contemporary clinical approaches, andrology, ART and antioxidants (pp. 497-508). Cham, Switzerland: Springer.

Agarwal, A., Majzoub, A., Esteves, S. C., Ko, E., Ramasamy, R., \& Zini, A. (2016). Clinical utility of sperm DNA fragmentation testing: Practice recommendations based on clinical scenarios. Translational Andrology and Urology, 5(6), 935. https://doi.org/10.21037/tau.2016.10.03

Ahima, R. S. (2008). Revisiting leptin's role in obesity and weight loss. Journal of Clinical Investigation, 118(7), 2380. https://doi.org/10.1172/ $\mathrm{JCl} 36284$

Alberti, K., Eckel, R. H., Grundy, S. M., Zimmet, P. Z., Cleeman, J. I., Donato, K. A., ... Smith, S. C. (2009). Harmonizing the metabolic syndrome: A Joint Interim Statement of the International Diabetes Federation Task Force on Epidemiology and Prevention; National Heart, Lung, and Blood Institute; American Heart Association; World Heart Federation; International Atherosclerosis Society; and International Association for the Study of Obesity. Circulation, 120(16), 16401650. https://doi.org/10.1161/CIRCULATIONAHA.109.192644

Alhashem, F., Alkhateeb, M., Sakr, H., Alshahrani, M., Alsunaidi, M., Elrefaey, H., ... Khalil, M. A. (2014). Exercise protects against obesity induced semen abnormalities via downregulating stem cell factor, upregulating Ghrelin and normalizing oxidative stress. EXCLI Journal, 13, 551-572.

Almabhouh, F., Aziz, N. A. A. A., Durairajanayagam, D., \& Singh, H. J. (2020). Could leptin be responsible for the reproductive dysfunction in obese men? Reproductive Biology, 20, 106-110. https://doi. org/10.1016/j.repbio.2020.01.003

Almabhouh, F. A., Md Mokhtar, A. H., Malik, I. A., Aziz, N. A. A. A., Durairajanayagam, D., \& Singh, H. J. (2020). Leptin and reproductive dysfunction in obese men. Andrologia, 52(1), e13433. https://doi. org/10.1111/and.13433

Álvarez-Castro, P., Pena, L., \& Cordido, F. (2013). Ghrelin in obesity, physiological and pharmacological considerations. Mini Reviews in Medicinal Chemistry, 13(4), 541-552.

Barja, G. (2014). The mitochondrial free radical theory of aging (Vol. 127, pp. 1-27). Amsterdam, the Netherlands: Elsevier B.V.

Benchaib, M., Lornage, J., Mazoyer, C., Lejeune, H., Salle, B., \& Guerin, J. F. (2007). Sperm deoxyribonucleic acid fragmentation as a prognostic indicator of assisted reproductive technology outcome. Fertility and Sterility, 87(1), 93-100. https://doi.org/10.1016/j.fertn stert.2006.05.057

Bendre, S. V., Murray, P. J., \& Basaria, S. (2015). Clomiphene citrate effectively increases testosterone in obese, young, hypogonadal men. Reproductive System \& Sexual Disorders: Current Research, 4(4). 155. https://doi.org/10.4172/2161-038X.1000155

Bessesen, D., Hill, J., \& Wyatt, H. (2004). Hormones and obesity. Journal of Clinical Endocrinology \& Metabolism, 89(4), E2. 
Bhat, G. K., Sea, T. L., Olatinwo, M. O., Simorangkir, D., Ford, G. D., Ford, B. D., \& Mann, D. R. (2006). Influence of a leptin deficiency on testicular morphology, germ cell apoptosis, and expression levels of apoptosis-related genes in the mouse. Journal of Andrology, 27(2), 302-310. https://doi.org/10.2164/jandrol.05133

Bieniek, J. M., Kashanian, J. A., Deibert, C. M., Grober, E. D., Lo, K. C., Brannigan, R. E., ... Jarvi, K. A. (2016). Influence of increasing body mass index on semen and reproductive hormonal parameters in a multi-institutional cohort of subfertile men. Fertility and Sterility, 106(5), 1070-1075. https://doi.org/10.1016/j.fertn stert.2016.06.041

Biswas, A., D'souza, U. J. A., \& Bhat, S. (2017). Dietary hypercholesterolemia induces oxidative stress challenging spermatogenesis in rat model: A link to possible infertility. International Journal of Pharmacological Science Research, 8(12), 5065-5071.

Blache, D., Zhang, S., \& Martin, G. (2003). Fertility in male sheep: Modulators of the acute effects of nutrition on the reproductive axis of male sheep. Reproduction, 61, 387-402.

Caprio, M., Isidori, A. M., Carta, A. R., Moretti, C., Dufau, M. L., \& Fabbri, A. (1999). Expression of functional leptin receptors in rodent Leydig cells. Endocrinology, 140(11), 4939-4947.

Carlsen, E., Giwercman, A., Keiding, N., \& Skakkebæk, N. E. (1992). Evidence for decreasing quality of semen during past 50 years. BMJ, 305(6854), 609-613.

Castro, A., Macedo-de la Concha, L., \& Pantoja-Meléndez, C. (2017). Low-grade inflammation and its relation to obesity and chronic degenerative diseases. Revista Médica del Hospital General de México, 80(2), 101-105. https://doi.org/10.1016/j.hgmx.2016.06.011

Chavarro, J. E., Toth, T. L., Wright, D. L., Meeker, J. D., \& Hauser, R. (2010). Body mass index in relation to semen quality, sperm DNA integrity, and serum reproductive hormone levels among men attending an infertility clinic. Fertility and Sterility, 93(7), 2222-2231. https://doi. org/10.1016/j.fertnstert.2009.01.100

Chimento, A., Sirianni, R., Casaburi, I., \& Pezzi, V. (2014). Role of estrogen receptors and $G$ protein-coupled estrogen receptor in regulation of hypothalamus-pituitary-testis axis and spermatogenesis. Frontiers in Endocrinology, 5, 1. https://doi.org/10.3389/ fendo.2014.00001

Clarke, H., Dhillo, W. S., \& Jayasena, C. N. (2015). Comprehensive review on kisspeptin and its role in reproductive disorders. Endocrinology and Metabolism, 30(2), 124-141. https://doi.org/10.3803/ EnM.2015.30.2.124

Danielewicz, A., Przybyłowicz, K. E., \& Przybyłowicz, M. (2018). Dietary patterns and poor semen quality risk in men: A cross-sectional study. Nutrients, 10(9), 1162. https://doi.org/10.3390/nu10091162

Davidson, L. M., Millar, K., Jones, C., Fatum, M., \& Coward, K. (2015). Deleterious effects of obesity upon the hormonal and molecular mechanisms controlling spermatogenesis and male fertility. Human Fertility, 18(3), 184-193. https://doi.org/10.3109/14647 273.2015.1070438

De Rooij, D., Van Alphen, M., \& Van de Kant, H. (1986). Duration of the cycle of the seminiferous epithelium and its stages in the rhesus monkey (Macaca mulatta). Biology of Reproduction, 35(3), 587-591.

Deepinder, F., Cocuzza, M., \& Agarwal, A. (2008). Should seminal oxidative stress measurement be offered routinely to men presenting for infertility evaluation? American Association of Clinical Endocrinologists, 14, 484-491.

di Frega, A. S., Dale, B., Di Matteo, L., \& Wilding, M. (2005). Secondary male factor infertility after Roux-en-Y gastric bypass for morbid obesity: Case report. Human Reproduction, 20(4), 997-998. https://doi. org/10.1093/humrep/deh707

Du Plessis, S. S., Cabler, S., McAlister, D. A., Sabanegh, E., \& Agarwal, A. (2010). The effect of obesity on sperm disorders and male infertility. Nature Reviews Urology, 7(3), 153-161. https://doi.org/10.1038/ nrurol.2010.6
Duffy, C. M., Nixon, J. P., \& Butterick, T. A. (2016). Orexin A attenuates palmitic acid-induced hypothalamic cell death. Molecular and Cellular Neuroscience, 75, 93-100. https://doi.org/10.1016/j. mcn.2016.07.003

Dutta, S., Biswas, A., \& Sengupta, P. (2019). Obesity, endocrine disruption and male infertility. Asian Pacific Journal of Reproduction, 8(5), 195-202. https://doi.org/10.4103/2305-0500.268133

Dutta, S., Biswas, A., Sengupta, P., \& Nwagha, U. (2019). Ghrelin and male reproduction. Asian Pacific Journal of Reproduction, 8(5), 227-232. https://doi.org/10.4103/2305-0500.268144

Dutta, S., Sengupta, P., \& Biswas, A. (2019). Adiponectin in male reproduction and infertility. Asian Pacific Journal of Reproduction, 8(5), 244-250. https://doi.org/10.4103/2305-0500.268153

Dutta, S., Sengupta, P., \& Muhamad, S. (2019). Male reproductive hormones and semen quality. Asian Pacific Journal of Reproduction, 8(5), 189-194. https://doi.org/10.4103/2305-0500.268132

Ferreira, C., Rabaca, A., Alves, M. G., Sousa, M., Rabaça, A., Oliveira, P. F., \& Sá, R. (2015). Impact of metformin on male reproduction investigation of the molecular and cellular process involved in selenium and a new form of thioamide ability to prevent doxorubicin toxicity in sertoli and sperm cells view project obesitility-gut hormones and test. Current Pharmaceutical Design, 21, 3621-3633.

Flehmig, G., Scholz, M., Klöting, N., Fasshauer, M., Tönjes, A., Stumvoll, M., ... Blüher, M. (2014). Identification of adipokine clusters related to parameters of fat mass, insulin sensitivity and inflammation. PLoS ONE, 9(6), e99785. https://doi.org/10.1371/journ al.pone.0099785

Garolla, A., Torino, M., Sartini, B., Cosci, I., Patassini, C., Carraro, U., \& Foresta, C. (2013). Seminal and molecular evidence that sauna exposure affects human spermatogenesis. Human Reproduction, 28(4), 877-885. https://doi.org/10.1093/humrep/det020

Gaskins, A. J., Colaci, D. S., Mendiola, J., Swan, S. H., \& Chavarro, J. E. (2012). Dietary patterns and semen quality in young men. Human Reproduction, 27(10), 2899-2907. https://doi.org/10.1093/humrep/ des298

Håkonsen, L. B., Thulstrup, A. M., Aggerholm, A. S., Olsen, J., Bonde, J. P., Andersen, C. Y., ... Ramlau-Hansen, C. H. (2011). Does weight loss improve semen quality and reproductive hormones? Results from a cohort of severely obese men. Reproductive Health, 8(1), 24. https:// doi.org/10.1186/1742-4755-8-24

Hammiche, F., Laven, J., Boxmeer, J., Dohle, G., Steegers, E., \& SteegersTheunissen, R. (2011). Sperm quality decline among men below 60 years of age undergoing IVF or ICSI treatment. Journal of Andrology, 32(1), 70-76. https://doi.org/10.2164/jandrol.109.009647

Hammoud, A. O., Gibson, M., Peterson, C. M., Hamilton, B. D., \& Carrell, D. T. (2006). Obesity and male reproductive potential. Journal of Andrology, 27(5), 619-626. https://doi.org/10.2164/jandr ol.106.000125

Hammoud, A. O., Gibson, M., Peterson, C. M., Meikle, A. W., \& Carrell, D. T. (2008). Impact of male obesity on infertility: A critical review of the current literature. Fertility and Sterility, 90(4), 897-904. https:// doi.org/10.1016/j.fertnstert.2008.08.026

Haslam, D. W., \& James, W. P. T. (2005). Obesity. Lancet (London, England), 366(9492), 1197-1209.

Hikim, A. S., \& Swerdloff, R. S. (1999). Hormonal and genetic control of germ cell apoptosis in the testis. Reviews of Reproduction, 4(1), 38-47. https://doi.org/10.1530/ror.0.0040038

Huang, P. L. (2009). A comprehensive definition for metabolic syndrome. Disease Models \& Mechanisms, 2(5-6), 231-237. https://doi. org/10.1242/dmm.001180

Irez, T., Karkada, I., Dutta, S., \& Sengupta, P. (2019). Obestatin in male reproduction and infertility. Asian Pacific Journal of Reproduction, 8(5), 239-243. https://doi.org/10.4103/2305-0500.268146

Ishikawa, T., Fujioka, H., Ishimura, T., Takenaka, A., \& Fujisawa, M. (2007). Ghrelin expression in human testis and serum testosterone level. 
Journal of Andrology, 28(2), 320-324. https://doi.org/10.2164/jandr ol.106.000810

Jarow, J., Sigman, M., \& Kolettis, P. (2011). The optimal evaluation of the infertile male: best practice statement reviewed and validity confirmed 2011. Paper presented at the American Urological Association.

Jensen, T., Andersson, A., Jorgensen, N., Andersen, A., Carlsen, E., Petersen, J., \& Skakkebak, N. (2004). Body mass index in relation to semen quality and reproductive hormonesamong 1,558 Danish men. Fertility and Sterility, 82(4), 863-870. https://doi.org/10.1016/j.fertn stert.2004.03.056

Jensen, T. K., Priskorn, L., Holmboe, S. A., Nassan, F. L., Andersson, A.-M., Dalgård, C., ... Jørgensen, N. (2020). Associations of fish oil supplement use with testicular function in young men. JAMA Network Open, 3(1), e1919462. https://doi.org/10.1001/jamanetwor kopen.2019.19462

Jia, Y.-F., Feng, Q., Ge, Z.-Y., Guo, Y., Zhou, F., Zhang, K.-S., ... Gu, Y.-Q. (2018). Obesity impairs male fertility through long-term effects on spermatogenesis. BMC Urology, 18(1), 42. https://doi.org/10.1186/ s12894-018-0360-5

Kahn, B. E., \& Brannigan, R. E. (2017). Obesity and male infertility. Current Opinion in Urology, 27(5), 441-445. https://doi.org/10.1097/ MOU.0000000000000417

Karayiannis, D., Kontogianni, M. D., Mendorou, C., Douka, L., Mastrominas, M., \& Yiannakouris, N. (2017). Association between adherence to the Mediterranean diet and semen quality parameters in male partners of couples attempting fertility. Human Reproduction, 32(1), 215-222.

Katib, A. (2015). Mechanisms linking obesity to male infertility. Central European Journal of Urology, 68(1), 79.

Kelly, T., Yang, W., Chen, C.-S., Reynolds, K., \& He, J. (2008). Global burden of obesity in 2005 and projections to 2030. International Journal of Obesity, 32(9), 1431-1437. https://doi.org/10.1038/ ijo.2008.102

Leisegang, K. (2019). Malnutrition and obesity. In R. Henkel, L. Samanta \& A. Agarwal (Eds.), Oxidants, antioxidants and impact of the oxidative status in male reproduction (pp. 117-134). Amsterdam, The Netherlands: Academic Press, Elsevier.

Leisegang, K., Bouic, P. J., \& Henkel, R. R. (2016). Metabolic syndrome is associated with increased seminal inflammatory cytokines and reproductive dysfunction in a case-controlled male cohort. American Journal of Reproductive Immunology, 76(2), 155-163. https://doi. org/10.1111/aji.12529

Leisegang, K., \& Henkel, R. (2018). The in vitro modulation of steroidogenesis by inflammatory cytokines and insulin in TM3 Leydig cells. Reproductive Biology and Endocrinology, 16(1), 26. https://doi. org/10.1186/s12958-018-0341-2

Leisegang, K., Henkel, R., \& Agarwal, A. (2017). Redox regulation of fertility in aging male and the role of antioxidants: A savior or stressor Current Pharmaceutical Design, 23(30), 4438-4450. https://doi. org/10.2174/1381612822666161019150241

Leisegang, K., Henkel, R., \& Agarwal, A. (2019). Obesity and metabolic syndrome associated with systemic inflammation and the impact on the male reproductive system. American Journal of Reproductive Immunology, 82(5), 1-14. https://doi.org/10.1111/aji.13178

Leisegang, K., Udodong, A., Bouic, P., \& Henkel, R. (2014). Effect of the metabolic syndrome on male reproductive function: A case-controlled pilot study. Andrologia, 46(2), 167-176. https://doi. org/10.1111/and.12060

Li, C., Dong, Z., Lan, X., Zhang, X., \& Li, S. (2015). Endoplasmic reticulum stress promotes the apoptosis of testicular germ cells in hyperlipidemic rats. Zhonghua Nan ke Xue, 21(5), 402-407.

Linabery, A. M., Nahhas, R. W., Johnson, W., Choh, A. C., Towne, B., Odegaard, A. O., ... Demerath, E. W. (2013). Stronger influence of maternal than paternal obesity on infant and early childhood body mass index. Pediatric Obesity, 8(3), 159-169.
Liu, Y., \& Ding, Z. (2017). Obesity, a serious etiologic factor for male subfertility in modern society. Reproduction, 154(4), R123-R131. https:// doi.org/10.1530/REP-17-0161

Malik, I. A., Durairajanayagam, D., \& Singh, H. J. (2019). Leptin and its actions on reproduction in males. Asian Journal of Andrology, 21(3), 296. https://doi.org/10.4103/aja.aja_98_18

Maneesh, M., \& Jayalekshmi, H. (2006). Role of reactive oxygen species and antioxidants on pathophysiology of male reproduction. Indian Journal of Clinical Biochemistry, 21(2), 80-89.

Maresch, C. C., Stute, D. C., Alves, M. G., Oliveira, P. F., de Kretser, D. M., \& Linn, T. (2017). Diabetes-induced hyperglycemia impairs male reproductive function: A systematic review. Human Reproduction Update, 24(1), 86-105. https://doi.org/10.1093/humupd/dmx033

Martins, A. D., Majzoub, A., \& Agawal, A. (2019). Metabolic syndrome and male fertility. World Journal of Men's Health, 37(2), 113-113. https://doi.org/10.5534/wjmh.180055

McPherson, N. O., \& Lane, M. (2015). Male obesity and subfertility, is it really about increased adiposity? Asian Journal of Andrology, 17(3), 450.

Meldrum, D. R., Morris, M. A., \& Gambone, J. C. (2017). Obesity pandemic: Causes, consequences, and solutions-But do we have the will? Fertility and Sterility, 107(4), 833-839. https://doi.org/10.1016/j. fertnstert.2017.02.104

Mir, J., Franken, D., Andrabi, S. W., Ashraf, M., \& Rao, K. (2018). Impact of weight loss on sperm DNA integrity in obese men. Andrologia, 50(4), e12957. https://doi.org/10.1111/and.12957

Moatt, J. P., Nakagawa, S., Lagisz, M., \& Walling, C. A. (2016). The effect of dietary restriction on reproduction: A meta-analytic perspective. BMC Evolutionary Biology, 16(1), 1-9. https://doi.org/10.1186/s1286 2-016-0768-z

Montanino Oliva, M., Minutolo, E., Lippa, A., laconianni, P., \& Vaiarelli, A. (2016). Effect of myoinositol and antioxidants on sperm quality in men with metabolic syndrome. International Journal of Endocrinology, 2016, 1674950

Mora-Esteves, C., \& Shin, D. (2013). Nutrient supplementation: Improving male fertility fourfold. Seminars in Reproductive Medicine, 31(4), 293300. https://doi.org/10.1055/s-0033-1345277

Mounzih, K., Lu, R., \& Chehab, F. F. (1997). Leptin treatment rescues the sterility of genetically obese ob/ob males. Endocrinology, 138(3), 1190-1193. https://doi.org/10.1210/endo.138.3.5024

Ng, M., Fleming, T., Robinson, M., Thomson, B., Graetz, N., Margono, C., ... Gakidou, E. (2014). Global, regional, and national prevalence of overweight and obesity in children and adults during 1980-2013: A systematic analysis for the Global Burden of Disease Study 2013. Lancet, 384(9945), 766-781.

Ojeda, S. R., Lomniczi, A., Mastronardi, C., Heger, S., Roth, C., Parent, A.-S., ... Mungenast, A. E. (2006). Minireview: The neuroendocrine regulation of puberty: Is the time ripe for a systems biology approach? Endocrinology, 147(3), 1166-1174. https://doi.org/10.1210/ en.2005-1136

Okorodudu, D., Jumean, M., Montori, V. M., Romero-Corral, A., Somers, V., Erwin, P., \& Lopez-Jimenez, F. (2010). Diagnostic performance of body mass index to identify obesity as defined by body adiposity: A systematic review and meta-analysis. International Journal of Obesity, 34(5), 791. https://doi.org/10.1038/ijo.2010.5

Page, S. T., Herbst, K. L., Amory, J. K., Coviello, A. D., Anawalt, B. D., Matsumoto, A. M., \& Bremner, W. J. (2005). Testosterone administration suppresses adiponectin levels in men. Journal of Andrology, 26(1), 85-92.

Panner Selvam, M., Sengupta, P., \& Agarwal, A. (2020). Sperm DNA fragmentation and male infertility. In M. Arafa (Ed.), Genetics of male infertility. Basel, Switzerland: Springer Nature.

Payab, M., Hasani-Ranjbar, S., Shahbal, N., Qorbani, M., Aletaha, A., Haghi-Aminjan, H., ... Hassani, S. (2019). Effect of the herbal medicines in obesity and metabolic syndrome: A systematic review and 
meta-analysis of clinical trials. Phytotherapy Research, 34, 526-545. https://doi.org/10.1002/ptr.6547

Perez-Leighton, C., Butterick-Peterson, T., Billington, C., \& Kotz, C. (2013). Role of orexin receptors in obesity: From cellular to behavioral evidence. International Journal of Obesity, 37(2), 167-174. https://doi.org/10.1038/ijo.2012.30

Ramos, C. F., \& Zamoner, A. (2014). Thyroid hormone and leptin in the testis. Frontiers in Endocrinology, 5, 198. https://doi.org/10.3389/ fendo.2014.00198

Reis, L. O., \& Dias, F. G. F. (2012). Male fertility, obesity, and bariatric surgery. Reproductive Sciences, 19(8), 778-785. https://doi. org/10.1177/1933719112440053

Ring, J. D., Lwin, A. A., \& Köhler, T. S. (2016). Current medical management of endocrine-related male infertility. Asian Journal of Andrology, 18(3), 357. https://doi.org/10.4103/1008-682X.179252

Roth, M. Y., Amory, J. K., \& Page, S. T. (2008). Treatment of male infertility secondary to morbid obesity. Nature Clinical Practice Endocrinology and Metabolism, 4(7), 415-419. https://doi.org/10.1038/ncpen dmet0844

Roychoudhury, S., Agarwal, A., Virk, G., \& Cho, C. L. (2017). Potential role of green tea catechins in the management of oxidative stress-associated infertility. Reproductive BioMedicine Online, 34(5), 487-498. https://doi.org/10.1016/j.rbmo.2017.02.006

Salas-Huetos, A., Bulló, M., \& Salas-Salvadó, J. (2017). Dietary patterns, foods and nutrients in male fertility parameters and fecundability: A systematic review of observational studies. Human Reproduction Update, 23(4), 371-389. https://doi.org/10.1093/humupd/dm×006

Salazar, M., Sánchez, J., Álvarez, P., Frusch, J., \& Mejía, R. (2018). The impact of obesity on fertility. Journal of Reproduction Gynecology and Obstetics, 3(009), 1-3.

Sansone, A., Sansone, M., Vaamonde, D., Sgrò, P., Salzano, C., Romanelli, F., ... Di Luigi, L. (2018). Sport, doping and male fertility. Reproductive Biology and Endocrinology, 16(1), 114. https://doi.org/10.1186/s1295 8-018-0435-x

Sarwer, D. B., Hanson, A. J., Voeller, J., \& Steffen, K. (2018). Obesity and sexual functioning. Current Obesity Reports, 7(4), 301-307. https:// doi.org/10.1007/s13679-018-0319-6

Schliep, K. C., Mumford, S. L., Ahrens, K. A., Hotaling, J. M., Carrell, D. T., Link, M., ... Hammoud, A. O. (2015). Effect of male and female body mass index on pregnancy and live birth success after in vitro fertilization. Fertility and Sterility, 103(2), 388-395.

Schulster, M., Bernie, A. M., \& Ramasamy, R. (2016). The role of estradiol in male reproductive function. Asian Journal of Andrology, 18(3), 435. https://doi.org/10.4103/1008-682X.173932

Seftel, A. (2006). Male hypogonadism. Part II: Etiology, pathophysiology, and diagnosis. International Journal of Impotence Research, 18(3), 223.

Sengupta, P., Agarwal, A., Pogrebetskaya, M., Roychoudhury, S., Durairajanayagam, D., \& Henkel, R. (2018). Role of Withania somnifera (Ashwagandha) in the management of male infertility. Reproductive BioMedicine Online, 36(3), 311-326. https://doi.org/10.1016/j. rbmo.2017.11.007

Sengupta, P., Bhattacharya, K., \& Dutta, S. (2019). Leptin and male reproduction. Asian Pacific Journal of Reproduction, 8(5), 220-226. https:// doi.org/10.4103/2305-0500.268143

Sengupta, P., Dutta, S., \& Krajewska-Kulak, E. (2017). The disappearing sperms: Analysis of reports published between 1980 and 2015. American Journal of Men's Health, 11(4), 1279-1304. https://doi. org $/ 10.1177 / 1557988316643383$

Sengupta, P., Dutta, S., Tusimin, M. B., İrez, T., \& Krajewska-Kulak, E. (2018). Sperm counts in Asian men: Reviewing the trend of past 50 years. Asian Pacific Journal of Reproduction, 7(2), 87-92. https://doi. org/10.4103/2305-0500.228018

Sengupta, P., Dutta, S., Tusimin, M., \& Karkada, I. (2019). Orexins and male reproduction. Asian Pacific Journal of Reproduction, 8(5), 233238. https://doi.org/10.4103/2305-0500.268145
Sermondade, N., Dupont, C., Faure, C., Boubaya, M., Cédrin-Durnerin, I., Chavatte-Palmer, P., ... Lévy, R. (2013). Body mass index is not associated with sperm-zona pellucida binding ability in subfertile males. Asian Journal of Andrology, 15(5), 626-629. https://doi.org/10.1038/aja.2013.10

Sermondade, N., Massin, N., Boitrelle, F., Pfeffer, J., Eustache, F., Sifer, C., ... Lévy, R. (2012). Sperm parameters and male fertility after bariatric surgery: Three case series. Reproductive BioMedicine Online, 24(2), 206-210. https://doi.org/10.1016/j.rbmo.2011.10.014

Setayesh, T., Nersesyan, A., Mišík, M., Ferk, F., Langie, S., Andrade, V. M., Knasmüller, S. (2018). Impact of obesity and overweight on DNA stability: Few facts and many hypotheses. In Mutation research/ reviews in mutation research (Vol. 777, pp. 64-91). Amsterdam, the Netherlands: Elsevier B.V.

Shamloul, R., \& Ghanem, H. (2013). Erectile dysfunction. Lancet, 381(9861), 153-165.

Singh, H., Pragasam, S. J., \& Venkatesan, V. (2018). Emerging therapeutic targets for metabolic syndrome: Lessons from animal models. Endocrine, Metabolic \& Immune Disorders - Drug Targets, 19(4), 481489. https://doi.org/10.2174/1871530319666181130142642

Sitzmann, B. D., Brown, D. I., Garyfallou, V. T., Kohama, S. G., Mattison, J. A., Ingram, D. K., ... Urbanski, H. F. (2014). Impact of moderate calorie restriction on testicular morphology and endocrine function in adult rhesus macaques (Macaca mulatta). AGE, 36, 183-197. https:// doi.org/10.1007/s11357-013-9563-6

Soubry, A., Guo, L., Huang, Z., Hoyo, C., Romanus, S., Price, T., \& Murphy, S. K. (2016). Obesity-related DNA methylation at imprinted genes in human sperm: Results from the TIEGER study. Clinical Epigenetics, 8(1), 51. https://doi.org/10.1186/s13148-016-0217-2

Soubry, A., Schildkraut, J. M., Murtha, A., Wang, F., Huang, Z., Bernal, A., ... Hoyo, C. (2013). Paternal obesity is associated with IGF2 hypomethylation in newborns: Results from a Newborn Epigenetics Study (NEST) cohort. BMC Medicine, 11(1), 29. https://doi. org/10.1186/1741-7015-11-29

Stephens, S., \& Polotsky, A. (2013). Big enough for an aromatase inhibitor? How adiposity affects male fertility. Seminars in Reproductive Medicine, 31(4), 251-257. https://doi.org/10.1055/s-0033-1345272

Tall, A. R., \& Yvan-Charvet, L. (2015). Cholesterol, inflammation and innate immunity. Nature Reviews Immunology, 15(2), 104.

Teerds, K., De Rooij, D., \& Keijer, J. (2011). Functional relationship between obesity and male reproduction: From humans to animal models. Human Reproduction Update, 17(5), 667-683.

Thaler, J. P., \& Schwartz, M. W. (2010). Minireview: Inflammation and obesity pathogenesis: The hypothalamus heats up. Endocrinology, 151(9), 4109-4115.

Tsai, E. C., Matsumoto, A. M., Fujimoto, W. Y., \& Boyko, E. J. (2004). Association of bioavailable, free, and total testosterone with insulin resistance: Influence of sex hormone-binding globulin and body fat. Diabetes Care, 27(4), 861-868.

Umul, M., Köse, S., Bilen, E., Altuncu, A., Oksay, T., \& Güney, M. (2015). Effect of increasing paternal body mass index on pregnancy and live birth rates in couples undergoing intracytoplasmic sperm injection. Andrologia, 47(3), 360-364.

Wang, C., Jackson, G., Jones, T. H., Matsumoto, A. M., Nehra, A., Perelman, M. A., ... Cunningham, G. (2011). Low testosterone associated with obesity and the metabolic syndrome contributes to sexual dysfunction and cardiovascular disease risk in men with type 2 diabetes. Diabetes Care, 34(7), 1669-1675.

Wei, Y., Chen, Q., \& Qian, W. (2018). Effect of bariatric surgery on semen parameters: A systematic review and meta-analysis. Medical Science Monitor Basic Research, 24, 188-197.

WHO (2000). Obesity: preventing and managing the global epidemic, p. 252. Report of a WHO consultation. https://www.who.int/nutrition/ publications/obesity/WHO_TRS_894/en/

WHO (2010). WHO laboratory manual for the examination and processing of human semen (5th ed.). Geneva, Switzerland: WHO. 
Winter, A. G., Zhao, F., \& Lee, R. K. (2014). Androgen deficiency and metabolic syndrome in men. Translational Andrology and Urology, 3(1), 50-58.

Wofford, M. R., King, D. S., \& Harrell, T. K. (2006). Drug-induced metabolic syndrome. Journal of Clinical Hypertension (Greenwich), 8(2), 114-119. https://doi.org/10.1111/j.1524-6175.2006.04751.x

Wolfe, A., \& Hussain, M. A. (2018). The emerging role(s) for kisspeptin in metabolism in mammals. Frontiers in Endocrinology, 9, 184. https:// doi.org/10.3389/fendo.2018.00184

Yamagishi, S. I., Edelstein, D., Du, X. L., Kaneda, Y., Guzman, M., \& Brownlee, M. (2001). Leptin induces mitochondrial superoxide production and monocyte chemoattractant protein-1 expression in aortic endothelial cells by increasing fatty acid oxidation via protein kinase A. Journal of Biological Chemistry, 276(27), 25096-25100. https://doi.org/10.1074/jbc.M007383200

Ye, J., Luo, D., Xu, X., Sun, M., Su, X., Tian, Z., ... Guan, Q. (2019). Metformin improves fertility in obese males by alleviating oxidative stress-induced blood-testis barrier damage. Oxidative Medicine and Cellular Longevity, 2019, 1-17. https://doi.org/10.1155/2019/9151067
Yu, Q., Li, T., Li, J., Zhong, L., \& Mao, X. (2017). Nitric oxide synthase in male urological and andrologic functions. In S. S. S. Saravi (Ed.), Nitric oxide synthase-simple enzyme-complex roles (pp. 1-10). InTech.

Zheng, D., Zhao, Y., Shen, Y., Chang, X., Ju, S., \& Guo, L. (2014). Orexin A-mediated stimulation of $3 \beta$-HSD expression and testosterone production through MAPK signaling pathways in primary rat Leydig cells. Journal of Endocrinological Investigation, 37(3), 285-292. https:// doi.org/10.1007/s40618-013-0035-8

How to cite this article: Leisegang K, Sengupta P, Agarwal A, Henkel R. Obesity and male infertility: Mechanisms and management. Andrologia. 2021;53:e13617. https://doi. org/10.1111/and.13617 